\title{
Study of phenolic compounds and antioxidant activity of Nectaroscordum tripedale Trautv in the natural conditions of Dagestan
}

\author{
Asiyat Alibegova*, Ziyarat Guseinova, and Fatima Islamova \\ Mountain Botanical Garden DFRS RAS, 367000, str. 75 Yaragskogo, Makhachkala, \\ Russian Federation
}

\begin{abstract}
The paper presents the results of studies devoted to the study of the rare for Dagestan species Nectaroscordum tripedale Trautv., Included in the Red Data Books of Russia and Dagestan, as endangered (rarity category 1). The aim of this work was to assess the content of phenolic compounds and the antioxidant activity of the aerial part of $\mathrm{N}$. tripedale. Plant raw materials were collected in the vegetation and flowering phase, and the content of phenolic compounds was studied, both in fresh raw materials and in frozen ones. Determination of the content of phenolic compounds and antioxidant activity was carried out in water - ethanol extracts $(70 \%$ ethanol solution) according to standard methods. The content of phenolic compounds is higher in fresh raw materials than in dried ones. The analysis showed that the leaves contain more flavonoids and anthocyanins than the rest, and the least of them is in the flower arrows. Evaluation of the total content of antioxidants in water - ethanol extracts from the aboveground part of the Dagestan N. tripedale samples. The data of phytochemical studies are of great importance and contribute to supplementing the available information on the dynamics of the accumulation of primary and secondary metabolites in herbaceous plants on the territory of Dagestan.
\end{abstract}

\section{Introduction}

For a long time, various species of the Alliaceae family have been widely used throughout the world as food, medicinal and ornamental plants. One of these interesting representatives is Nectaroscordum tripedale (Trautvetter) A. Grossh., Or Allium tripedale (Trautvetter) A. Grossh. This species is very rare in the Caucasus. Distributed in Azerbaijan, South Transcaucasia, Iraq, Iran, Turkey. In the mountainous regions of northwestern Iran, despite the presence of a very strong and somewhat unpleasant taste, N. tripedale leaves are widely used by the local population as a spicy vegetable, and are also added to the preparation of local bread as a flavoring agent $[1,2]$. Due to its beautiful inflorescences, it is also used as an ornamental plant.

${ }^{*}$ Corresponding author: aidamirova1@mail.ru 
A review of scientific works on the phytochemical study of species of the genus showed that N. tripedale was traditionally used in folk medicine as a medicinal plant for the treatment of infections, since it is known that onion phytoncides have bactericidal, protistocidal, antifungal and medicinal properties. A number of works are devoted to the study of the antifungal activity of N. tripedale extracts against various Candida species [3], some pathogenic dermatophytes [4], yeast [5]. The scolicidal effect of $N$. tripedale extract in a mouse model [6], essential oil against protoscoleses of echinococcal cysts [7], a positive effect on liver and kidney function in rats with streptozotocin-induced diabetes in experimental conditions $[8,9]$ was also noted. N. tripedale versus lamblia [1], the effect of the toxicity of $\mathrm{N}$. tripedale extract on hematological and biochemical parameters in mice [10], the protective effect of $\mathrm{N}$. tripedale extract and its bioactive component tetramethylpyrazine against hepatotoxicity caused by acetaminophen in rats [11].

A phytochemical study of $N$. tripedale revealed the content of cysteine-sulfoxides and volatile sulfur compounds [12], two cinnamic acid derivatives were identified in $\mathrm{N}$. tripedale bulbs, which are pharmacologically active phenolic compounds [13], and two phenylpropanoid glycosides were also found in chloroform-methanol 2 extract of bulbs [ ].

As for other Nectaroscordum species, there are publications in the literature on the study of polyphenolic substances and the antioxidant activity of Nectaroscordum siculum ssp.bulgaricum (Janka) Stearn (N. dioscoridis), growing in Bulgaria and used as a traditional culinary seasoning from South-Eastern Europe. [14, 15], according to the properties of Nectaroscordum koelzi [1, 16, 17].

During the taxonomic and geographical study of species of the Alliaceae family in the Caucasus, it was confirmed that N. tripedale is the only representative of the genus Nectaroscordum in this region [18].

In our country, N. tripedale is included in the Red Data Books of Russia and Dagestan as endangered (rare category 1) [19-21]. Active anthropogenic activity (deforestation, grazing, recreation) leads to the destruction of habitats and a decrease in the number of its populations due to the destruction of plants. The species is protected in the Samur National Park (cluster "Samura Delta") [22] and the natural park "Dzhalgan". In the 1980s, work began on the cultivation of $\mathrm{N}$. tripedale in the vicinity of the city of Makhachkala (50 meters above sea level) and its comprehensive study under conditions of introduction [23, 24]. At present, it is translocated from the Dzhalgan mountain to the Samur forest and Talga gorge $[25,26]$.

In the Caucasus, the classic locality of this species is: Isti - su in Daralagez (Nakhichevan, Azerbaijan), where it grows in rock crevices [27-29]. In Dagestan, it occurs in Magaramkent (environs of the Primorsky village) [30] and Derbent (Zidyan-Kemakh village) regions [25]. In recent years, it has also been identified on Mount Dzhalgan [23]. In the Caucasus, the species is found in the Southwestern Transcaucasia and South Transcaucasia. The general range of the species: Southwest Asia (Turkey, Iran, Iraq) [18, 32].

Thus, an analysis of the literature data showed that information on the chemical composition of Nectaroscordum species is very limited, and is mainly devoted to the study of the medicinal properties of this species and the content of some compounds, and there are no works on the phytochemical study of Dagestan samples at all.

An increase in the scale of the growing destruction of natural complexes, habitats of plant and animal species leads to a decrease in the number of an increasing number of species to a critical level, especially rare and endemic ones, dooming them to extinction. For the development and adoption of measures to preserve species diversity, it is important to comprehensively study the biology and ecology of species, including the chemical composition of plants and its variability, to identify microevolutionary mechanisms of resistance and adaptive potential of resource, rare and endemic species, including. 


\section{Methods}

Due to the fact that studies on rare and endangered species remain relevant, and the lack of data on the phytochemical study of the Dagestan populations of N. tripedale, the purpose of this study was to determine the total content of phenolic compounds and antioxidants in various plant organs of samples collected in the natural conditions of Dagestan. (Russia) during the growing season and flowering, to supplement the data on biology and ecology obtained earlier.

Due to the relevance of studies on rare and endangered species and the lack of data on the phytochemical study of the Dagestan populations of N. tripedale, the purpose of this study was to determine the total content of phenolic compounds and antioxidants in various plant organs of samples collected in the natural conditions of Dagestan during the growing season and flowering, to complement the data on biology and ecology obtained earlier.

To achieve this goal, it was necessary to solve the following tasks: studying the herbarium fund, analyzing the literature data and determining the degree of study of $\mathrm{N}$. tripedale, clarifying the growing areas of the studied species, collecting raw materials for phytochemical analyzes in the growing season and flowering, drying the material for further work, preparing extracts, carrying out phytochemical analyzes with subsequent calculations and statistical processing of the data obtained.

Material for research was taken from one of the points where this species grows (Table 1). The collection of $\mathrm{N}$. tripedale plant materials was carried out twice: in April and June 2019: in the growing season and the flowering phase of plants, respectively. The material was dried to an air-dry state according to a generally accepted method in the shade in a well-ventilated area.

Table 1. Comparative characteristics of collection points for field material for study.

\begin{tabular}{|c|c|c|}
\hline Collection place & $\begin{array}{c}\text { Altitude above sea } \\
\text { level, } \mathrm{m} .\end{array}$ & Coordinates \\
\hline $\begin{array}{l}\text { Mount Dzhalgan, Derbent region, } \\
\text { Republic of Dagestan, Russia }\end{array}$ & 210 & $\mathrm{~N} 42^{\circ} 03^{\prime}, \mathrm{E} 48^{\circ} 16^{\prime}$ \\
\hline
\end{tabular}

An analytical sample of the analyzed plant object was preliminarily crushed to a particle size of no more than $10 \mathrm{~mm}$ using appropriate equipment and devices (scissors, a mill), and extracts were obtained in accordance with the procedure using a 70\% ethanol solution [33].

Determination of the content of phenolic compounds and antioxidant activity was carried out in water - ethanol extracts ( $70 \%$ ethanol solution) according to standard methods. To determine the total content of flavonoids in plant materials, a spectrophotometric method (at 408 - $616 \mathrm{~nm}$ ) was used, based on the reaction of complexation of flavonoids with aluminum chloride in an acidic medium (in terms of rutin) [31]. The determination of the total content of anthocyanins was carried out using a direct spectrophotometric method in the visible region $(450-550 \mathrm{~nm})$, which consists in direct measurement of optical density (in terms of cyanidin 3-glucoside) [34].

The determination of the total content of antioxidants was carried out by the amperometric method on a device for the rapid analysis of total antioxidants "Color Yauza 01 - AA", by the amperometric method based on measuring the electric current in an electrochemical cell that occurs when a certain potential is applied to the electrode. The total content of antioxidants was expressed in $\mathrm{mg} / \mathrm{g}$ (in terms of gallic acid) [35]. 
To determine the moisture content of the raw material (loss in weight on drying due to the removal of moisture and volatile substances), about $2.0 \mathrm{~g}$ of the crushed material (accurately weighed) was placed in a pre-weighed weighing bottle, dried in an oven at a temperature of $105^{\circ} \mathrm{C}$ until constant weight and weighed again [33].

The data obtained were processed statistically using the Statistika 5.5 licensed software package.

\section{Results}

In Dagestan, N. tripedale was first discovered in 1955 in the Samur river delta of the Magaramkent region in a hornbeam forest [30]. Later, this species was also found in the vicinity of the village of Zidyan, Derbent region (at an altitude of 500-600 meters above sea level) [31], and on the Dzhalgan mountain in the vicinity of the Naryn fortress - kala in a sparse light oak-hornbeam forest [21].

It grows in hornbeam-ash, oak-ash forests on lowlands and in the foothills up to 600 meters above sea level. Biological features of the species: bulbous spring ephemeroid, mesophyte, heat-loving, shade-tolerant species. The beginning of the growing season is late February - early March, flowering - at the end of May, in June-July [19-21].

In the 1980 s, work began on the cultivation of $\mathrm{N}$. tripedale in the vicinity of the city of Makhachkala (50 meters above sea level) [23]. As a result of long-term observations, the features of phenology, morphogenesis, seed and vegetative reproduction were studied. Vegetative renewal occurs through the formation of $1-2$ daughter bulbs, seed reproduction was observed in individuals at 8 - 9 years of age. Individuals of different ages differ in size and number of leaves. Under the conditions of Makhachkala, the species blooms, bears fruit and reproduces by self-sowing [23, 24].

At the moment, work is underway to study the populations of N. tripedale found on the territory of Dagestan: study of the state of natural populations, phytocenotic confinement of the species and the characteristics of its reproductive potential. On the Dzhalgan mountain, the three-foot nectar corpus is represented by uneven-aged individuals on an area of 300 $\mathrm{m}^{2}$, and in the vicinity of the village of Zidyan $-500 \mathrm{~m}^{2}$, and in the Samur forest it has not been found for a long time. Also, work was carried out to translocate the species from Mount Dzhalgan into natural conditions in the Samur forest and Talga gorge - 50 bulbs were transplanted each. It was revealed that $\mathrm{N}$. tripedale in natural populations forms a sufficient number of seeds that contribute to the self-maintenance of the species; Seed productivity of $\mathrm{N}$. tripedale in samples from a higher altitude (Zidyan, $600 \mathrm{~m}$ ), the number of seeds is less, and the mass of seeds is higher than in specimens from a lower altitude (Dzhalgan, $200 \mathrm{~m}$ ) [36, 37].

To clarify the places of growth, work was carried out to study the herbaria of the Mountain Botanical Garden and the Dagestan State University. According to the data obtained, as well as from our own observations in nature, it can be concluded that at present $\mathrm{N}$. tripedale is found in only a few points. Table 2 shows data characterizing the place and time of collection of a plant for a herbarium.

Table 2. Genus 2. Nectaroscordum Lindl. in the flora of Dagestan, Russia.

\begin{tabular}{|l|l|l|c|}
\hline \multicolumn{1}{|c|}{ Herbarium } & \multicolumn{1}{|c|}{ View } & \multicolumn{1}{c|}{ Collection area } & \multicolumn{1}{c|}{$\begin{array}{c}\text { Gathering } \\
\text { place }\end{array}$} \\
\hline \multirow{2}{*}{$\begin{array}{l}\text { Dagestan State } \\
\text { University }\end{array}$} & $\begin{array}{l}\text { N. tripedale (Trautv.) } \\
\text { Grossh. }\end{array}$ & $\begin{array}{l}\text { Kala village } \\
\text { Derbent region }\end{array}$ & Forest \\
\cline { 2 - 4 } & $\begin{array}{l}\text { Samur forest, } \\
\text { Derbent region }\end{array}$ & Forest \\
\hline Mountain Botanical & N. tripedale (Trautv.) & Dzhalgan mountain, Naryn- & Forest \\
\hline
\end{tabular}




\begin{tabular}{|l|l|l|l|}
\hline Garden & Grossh. & $\begin{array}{l}\text { Kala fortress, Derbent region } \\
(205 \text { meters above sea level })\end{array}$ & \\
\cline { 3 - 4 } & & $\begin{array}{l}\text { neighborhood village } \\
\text { Kemakh, Derbent region }\end{array}$ & Forest \\
\hline
\end{tabular}

The moisture content of $\mathrm{N}$. tripedale raw materials is quite high: from 70 to $93 \%$, which is typical for mesophilic plants. The plants were divided into parts, crushed and dried at room temperature in a well-ventilated area.

Research has been carried out on the phytochemical study of phenolic compounds of water-ethanol extracts $(70 \%$ ethanol solution) of samples of $\mathrm{N}$. tripedale aerial organs collected in the natural population of the flora of Dagestan in 2009 during the growing season, and later in the flowering phase.

The determination of the total content of flavonoids (SSF) and anthocyanins (CCA) in the raw material, and the total antioxidant activity (CAA) was carried out in different organs of N. tripedale - leaves, inflorescences, flower arrows (3 replicates) (table 3).

Since this species is endangered in Dagestan, in order to preserve individuals for chemical analysis, only the aerial part of the plants was taken, and the bulbs were not used. The results of phytochemical analysis of $\mathrm{N}$. tripedale plant materials collected in the natural conditions of Dagestan are presented in Table 3.

Table 3. The total content of phenolic compounds of natural populations N. tripedale (Trautv.)

Grossh., \% (Dzhalgan mountain, Republic of Dagestan, Russia, 2019).

\begin{tabular}{|c|c|c|c|c|}
\hline $\begin{array}{c}\text { Place of } \\
\text { collection of } \\
\text { raw materials }\end{array}$ & $\begin{array}{c}\text { Analyzed part } \\
\text { of plants }\end{array}$ & $\mathbf{N}$ & $\begin{array}{l}\text { Total content of } \\
\text { flavonoids, \% } \\
\bar{x} \pm S_{\bar{x}}\end{array}$ & $\begin{array}{c}\text { Total content of } \\
\text { anthocyanins, \% } \\
\bar{x} \pm S_{\bar{x}}\end{array}$ \\
\hline \multirow{3}{*}{$\begin{array}{l}\text { fresh raw } \\
\text { materials }\end{array}$} & Leaves & 3 & $1,946 \pm 0,003$ & $0,27 \pm 0,001$ \\
\hline & Inflorescences & 3 & $1,423 \pm 0,003$ & $0,058 \pm 0,000$ \\
\hline & Flower arrows & 3 & $0,639 \pm 0,001$ & $0,040 \pm 0,000$ \\
\hline \multirow{3}{*}{$\begin{array}{l}\text { dried raw } \\
\text { material }\end{array}$} & Leaves & 3 & $0,97 \pm 0,003$ & $0,14 \pm 0,001$ \\
\hline & Inflorescences & 3 & $0,863 \pm 0,001$ & $0,039 \pm 0,000$ \\
\hline & Flower arrows & 3 & $0,396 \pm 0,002$ & $0,031 \pm 0,000$ \\
\hline
\end{tabular}

The assessment of the total antioxidant activity in different organs of $N$. tripedale (fresh raw materials) is shown in table 4.

Table 4. The total content of antioxidants in different organs N. tripedale (Trautv.) Grossh. in natural conditions (Dzhalgan mountain, Republic of Dagestan, Russia, 2019).

\begin{tabular}{|l|l|c|c|}
\hline $\begin{array}{c}\text { Place of } \\
\text { collection of } \\
\text { raw materials }\end{array}$ & \multicolumn{1}{|c|}{$\begin{array}{c}\text { Analyzed part of } \\
\text { plants }\end{array}$} & $\mathbf{N}$ & $\begin{array}{c}\text { Total antioxidant content, } \\
\mathbf{m g} / \mathbf{g} \\
\bar{x} \pm S_{\bar{x}}\end{array}$ \\
\hline \multirow{3}{*}{$\begin{array}{c}\text { fresh raw } \\
\text { materials }\end{array}$} & Leaves & 3 & $1,20 \pm 0,01$ \\
\cline { 2 - 4 } & Inflorescences & 3 & $2,77 \pm 0,00$ \\
\cline { 2 - 4 } & Flower arrows & 3 & $0,56 \pm 0,01$ \\
\hline
\end{tabular}

The results of the analysis showed that in the inflorescences there is a high antioxidant activity, as well as the content of phenolic compounds. 


\section{Discussion}

As a result of phytochemical analysis of various organs of $\mathrm{N}$. tripedale, it was revealed that in all studied natural samples, regardless of the studied raw material and the analyzed part of the plant, the average total content of flavonoids ranges from $0.4 \%$ to $2 \%$, in terms of rutin, and the average total content anthocyanins from $0.04 \%$ to $0.27 \%$, in terms of cyanidin 3-glucoside (Table 3).

When comparing the results obtained for the content of flavonoids and anthocyanins in plant raw materials, it can be seen that the indicators are higher in the frozen sample than in the dried sample (Table 3).

The greatest accumulation of flavonoids and anthocyanins occurs in the leaves, which can be seen only in the vegetation phase of plants (1.95 and 0.27 , respectively), and the smallest in the flower arrows (0.64 and 0.04 , respectively). Leaves in the flowering phase of plants are already dry, since the species is a geophyte.

Phenolic compounds that are part of the plant antioxidant defense system play an important role in the adaptation of plants to environmental changes. It is known that they are stress metabolites, the biosynthesis of which is activated during the action of unfavorable environmental factors on plants, and can serve as markers of the level of plant adaptation to stress conditions.

Antioxidant activity is associated with the content of certain secondary metabolites. Comparison of the total content of antioxidants in organs of $\mathrm{N}$. tripedale also shows that it is higher in leaves than in inflorescences and flower arrows.

The data obtained in the study of the content of phenolic compounds in plants will be used to explain the mechanisms of variability in the content of secondary metabolites under the influence of a complex of abiotic environmental factors and adaptation of plants to environmental conditions. In the future, studies will be continued to obtain more complete information on the accumulation of secondary metabolites by plants in various organs.

The search and study of samples with a high content of antioxidants, for the selection of the most promising, with subsequent introduction into culture, arouses increased interest of researchers in such objects.

\section{Conclusion}

We were the first to study a Dagestan natural sample of N. tripedale for the total content of some phenolic compounds (flavonoids and anthocyanins) and the total content of antioxidants. The accumulation of flavonoids and anthocyanins was noted in the leaves during the growing season, and after drying of the leaves in the inflorescences and flower arrows.

The data of phytochemical studies are important in the assessment of species containing biologically active substances with high antioxidant activity, for further introduction of the species into culture, and also contribute to supplementing the available information on the dynamics of accumulation of primary and secondary metabolites in herbaceous plants on the territory of Dagestan, which makes it possible to identify them. role in plant ontogenesis and mechanisms of adaptation to growing conditions. Work on the study of phenolic compounds in N. tripedale will continue.

\section{References}

1. M. Rashidipour, BMJ Open, 7 (2017)

2. H. Ghaffari, M. Dinani, J. Rep. Pharm. Sci., 7 (2018) 
3. M. Shirani, A. Samimi, H. Kalantari, M. Madani, A. Zanganeh, Current Medical Mycology, 3, 1 (2017)

4. A. Sepahvand, B. Ezatpour, M. Niazi, M. Rashidipour, M. Aflatoonian, M. Soleimani, Entomology and Applied Science Letters, 5, 2 (2019)

5. S. Jahanbakhsh, K. Ebrahimi, M. Sepahvand, M. Niazi, F. Yari, A. Shakarami, F. Tarhani, S. Kharazi, Anti-Infective Agents, 18, 1 (2020)

6. H. Mahmoudvand, S. Nadri, S. Jahanbakhsh, Der Pharma Chem., 8 (2016)

7. H. Mahmoudvand, B. Ezatpour, M. Rashidipour, S. R. Mirbadie, Pak. J. Pharm. Sci., 29, 6 (2016)

8. S. Paydar, G. Jelodar, J. Mohammadi, N. Mohammadi, Iran J. Endocrinol. Metab., 18 (2016)

9. S. Ghobadi, D. Dastan, M. Soleimani, A. Nili-Ahmadabadi, Research in Pharmaceutical Sciences, 14, 488 (2019)

10. A. Kiani, B. Ezatpour, M. Niazi, S. Jahanbakhsh, Anti-Infective Agents, 18, 1 (2018)

11. A. Aidy, E. Karimi, H. Ghaneialvar, S. Mohammadpour, N. Abbasi, Advances in Traditional Medicine, 20, 2 (2020)

12. J. Kusterer, M. Keusgen, J. Agric Food Chem., 58, 2 (2010).

13. Z. Chehri, B. Zolfaghari, M. S. Dinani, Advanced Biomedical Research, 7, 1 (2018)

14. R. Vrancheva, M. Stoyanova, D. Mihaylova, I. Aneva, I. Deseva, N. Petkova, I. Ivanov, A. Pavlov, Int. Food Res. J., 26, 5 (2019)

15. R. Vrancheva, I. Dincheva, I. Aneva, A. Pavlov, Z. Naturforsch, 75 (2020)

16. K. Hasanvand, M. Khaksarian, M. Alipour, H. Mahmoudvand, M. Naizi, S. Nadri, Current Cancer Drug Targets, 20, 4 (2020)

17. M. Khaksarian, H. Mahmoudvand, M. Alipour, M. Naizi, K. Hasanvand, S. Nadri, Curr Drug Discov Technol., 18, 4 (2021)

18. G. Kudryashova, Botanicheskii Zhurnal, 88, 7 (2003)

19. P. Lvov, Red Book of the RSFSR. Plants (1988)

20. A. Raji, Sh. Guseinov, R. Murtazaliev, Red Data Book of the Russian Federation (plants and mushrooms), 1 (2008)

21. R. Murtazaliev, A. Teymurov, Red Data Book of the Republic of Dagestan. Plants, 53, $1(2009)$

22. Yu. Yarovenko, R. Murtazaliev, E. Ilyina, Reserved places of Dagestan, 96 (2004)

23. K. Ibragimov, S. Shirinova, Mountain plant resources: theory and forecast of development and reproduction (1999)

24. K. G. Ibragimov, Modern problems of adaptation and biodiversity (2006)

25. Z. A. Guseinova, R. A. Murtazaliev, Patterns of distribution, reproduction and adaptation of plants and animals (2010)

26. Z. Guseinova, R. Murtazaliev, Heritage of Academician N.V. Tsitsina. Current state and development prospects (2019)

27. A. Vvedensky, Flora of the USSR, 280, 4 (1935)

28. A. Grossheim, Flora of the Caucasus, 2 (1940)

29. A. Grossheim, Key to the Plants of the Caucasus (1949)

30. P. Lvov, Botanicheskii Zhurnal, 46, 8 (1961)

31. P. Lvov, Botanicheskii Zhurnal, 65, 4 (1980) 
32. G. Kudryashova, Botanicheskii Zhurnal, 77, 4 (1992)

33. State Pharmacopoeia of the USSR, 11, 1 (1998)

34. T. Kupchak, L. Nikolaeva, L. Shimolina, Plant resources, 3 (1995)

35. A. Yashin, Russian Chemical Journal, 1, 2 (2008)

36. Z. Guseinova, R. Murtazaliev, Species populations and communities in natural and anthropogenically transformed landscapes: state and methods of its diagnostics, 25 (2010)

37. Z. Guseinova, R. Murtazaliev, Use and protection of natural resources in Russia, 156, 4, (2018) 